Geografia e Ordenamento do Território, Revista Eletrónica

Centro de Estudos de Geografia e Ordenamento do Território

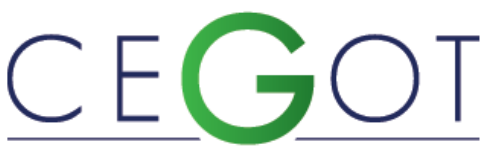

Centro de Estudos de Geografia

e Ordenamento do Território http://cegot.org

ISSN: 2182-1267

Santinha, G.

GOVCOPP, Departamento de Ciências Sociais,

Políticas e do Território, Universidade de Aveiro

g.santinha@ua.pt

Marques, T.

Faculdade de Letras da Universidade do Porto

teresasamarques@gmail.com

\title{
A integração do princípio de Coesão Territorial na agenda política: o caso português $^{1}$
}

Referência: Santinha, G. e Marques, T. (2012). A integração do princípio de Coesão Territorial na agenda política: o caso português. Revista de Geografia e Ordenamento do Território, n.o 2 (Dezembro). Centro de Estudos de Geografia e Ordenamento do Território. Pág. 215 a 244

\section{Resumo}

A publicação do Livro Verde sobre a Coesão Territorial (2008) e a ratificação do Tratado de Lisboa (2009) constituem marcos fundamentais para a adoção do princípio de Coesão Territorial enquanto novo paradigma de desenvolvimento do espaço europeu. No entanto, apesar da sua forte institucionalização, ainda se verifica alguma ambiguidade no que respeita ao seu conceito e operacionalização, preocupação que

\footnotetext{
${ }^{1}$ A reflexão aqui efetuada decorre de uma investigação em curso. Os resultados serão posteriormente complementados através da realização de entrevistas junto de determinados atores-chave envolvidos nos processos de elaboração dos instrumentos em análise. Refira-se, ainda, que este texto beneficiou dos comentários de dois revisores anónimos, pelo que fica expresso o nosso agradecimento.
} 
assume particular relevância quando os Estados-Membros, claramente influenciados pelas orientações da Comissão Europeia, procuram incluir este princípio na sua agenda política. Tendo como pano de fundo o caso português, é justamente sobre a transição do princípio de Coesão Territorial da agenda Europeia para a agenda nacional que este texto se debruça, analisando e articulando as interpretações existentes.

Palavras-chave: Coesão Territorial, políticas públicas, desenvolvimento territorial equilibrado, governança territorial

\begin{abstract}
With both the publication of the Green Paper on Territorial Cohesion (2008) and the enter into force of the Treaty of Lisbon (2009), the concept of Territorial Cohesion became enshrined as the new key objective of the European Union. Despite decreed as an essential goal for all Member States, there is still no agreement on how to define and achieve Territorial Cohesion in practical terms. This ambiguity represents a challenge to national and regional actors who try to respond to and articulate with the European Commission agenda and guidelines. Informed by the Portuguese case, the present paper analyses how the concept is being interpreted by the national policy agenda.
\end{abstract}

Keywords: Territorial Cohesion, public policies, balanced territorial development, territorial governance 


\section{Introdução}

De uma forma crescente, a dimensão territorial tem vindo a assumir visibilidade na formulação de políticas públicas. Sobretudo no contexto europeu, várias têm sido as instâncias que se têm vindo a debruçar sobre esta questão. As políticas da Comissão Europeia (CE), quer ao nível específico do ordenamento do território (uma matéria em relação à qual, refira-se, a União Europeia (UE) não tem competências formais), quer por intermédio da Política Regional e de Coesão (o principal instrumento da UE para perseguir um desenvolvimento harmonioso do espaço europeu), adotaram recentemente o princípio de Coesão Territorial como o novo paradigma de desenvolvimento do espaço europeu. Embora surgindo formalmente em 1997 no Tratado de Amesterdão, há quatro episódios institucionais posteriores que marcam um ponto de não retorno na adoção deste princípio do ponto de vista da política pública: a publicação da Agenda Territorial da União Europeia, primeiro em 2007 (CEC, 2007) e a versão renovada, TA2020, em 2011 (CEC, 2011), o lançamento do Livro Verde sobre a Coesão Territorial (CEC, 2008), a inclusão da Coesão Territorial no Tratado de Lisboa (2009) enquanto 3ำ pilar de atuação a par da Coesão Económica e da Coesão Social e, finalmente, o desenho da Estratégia Europa 2020, adotada em 2010 em substituição da Estratégia de Lisboa, com o intuito de relançar a economia europeia e na qual a Coesão Territorial surge como um dos principais objetivos a atingir.

Procurando reforçar a importância do território na agenda política ("territory matters" é uma expressão agora recorrente nas diversas políticas e relatórios de orientação comunitária), o princípio da Coesão Territorial surge no seio destas orientações com o intuito generalizado de alcançar o desenvolvimento harmonioso de todos os territórios, valorizar a sua diversidade e complementaridades e facultar a possibilidade da população tirar o melhor partido das características existentes em cada território. Sendo certo que o Livro Verde e a abertura do processo de consulta pública sobre o mesmo vieram procurar clarificar o que se entendia por Coesão Territorial e quais as políticas a tomar para se alcançar esse princípio, não é menos verdade que ainda se verifica alguma ambiguidade inerente ao seu conceito. E se ao nível da CE a ausência 
de uma definição clara revela-se útil para se encontrarem consensos políticos entre os 27 Estados-membros, já a sua implementação e operacionalização afigura-se mais complexa. Esta é, precisamente, uma preocupação que tem vindo a emergir nos últimos anos em diversos países, cujas orientações, claramente influenciadas pela agenda da $\mathrm{CE}$, apontam no sentido de se adotar o princípio da Coesão Territorial na formulação de políticas públicas.

É justamente sobre esta ausência de delimitação precisa do conceito e sobre a transição do princípio de Coesão Territorial da agenda Europeia para a agenda nacional que este texto se debruça. Através da análise de diversos instrumentos de orientação estratégica, procura esclarecer-se como o princípio de Coesão Territorial está a ser incorporado na agenda política portuguesa e, consequentemente, a ser interpretado pelas instituições públicas e outros atores-chave integrantes dos processos de tomada de decisão. O objetivo é produzir sugestões úteis que poderão contribuir para a melhoria dos processos de decisão e para a construção de um entendimento global do conceito em causa.

Tendo presente este objetivo, o texto encontra-se organizado em cinco partes. $\mathrm{Na}$ próxima, efetua-se uma revisão sucinta da emergência do princípio de Coesão Territorial e debate-se a ausência de uma definição clara do seu conceito. Nas três partes subsequentes, avança-se para o exercício analítico proposto apresentando, primeiro, a metodologia usada, depois, a forma como cada um dos instrumentos de orientação estratégica analisados aborda o princípio de Coesão Territorial e, por fim, uma interpretação do significado de Coesão Territorial à luz desses instrumentos. Na última parte, apresentam-se algumas notas finais realçando-se a importância de se clarificarem conceitos e, consequentemente, desenvolver medidas de política capazes de os operacionalizar.

\section{Coesão Territorial: um objetivo político, um debate conceptual inconclusivo}

Desde a sua génese que a UE tem por missão promover um desenvolvimento harmonioso das atividades económicas pela redução das disparidades entre as 
diversas regiões e do atraso das menos favorecidas (Tratado de Roma, 1957). Uma missão catapultada por Jacques Delors em 1986 com a adoção do Acto Único Europeu, estabelecendo uma política comunitária de Coesão Económica e Social com o objetivo de contrabalançar os efeitos da realização do mercado interno nos Estados-Membros menos desenvolvidos e de atenuar as disparidades de desenvolvimento verificadas entre as regiões. Com o decorrer do tempo, e seguindo as palavras de Gorzelak (2009, p. 259), "Cohesion has become one of the most important phrases in current policies conducted within the European Union (EU) member states and the European Union as such".

Surgindo formalmente com o Tratado de Amesterdão (1997), a Coesão Territorial vem dar corpo a esta preocupação com as disparidades, procurando incutir a importância do território na agenda política, não só europeia, mas também de cada EstadoMembro. Um conjunto de episódios institucionais mais recentes vem consolidar a Coesão Territorial enquanto novo objetivo político e paradigma de desenvolvimento do espaço europeu, entre os quais destacando-se a assinatura e ratificação do Tratado de Lisboa pelos Estados-Membros no qual este objetivo surge enquanto 3ㅇ pilar de atuação a par da Coesão Económica e da Coesão Social. Neste sentido, Coesão Territorial reforça a dimensão territorial da Política de Coesão e dos seus outros dois pilares e, de forma complementar, intensifica a ideia de coesão (e, consequentemente, a sua ligação à Política de Coesão) nas políticas de base territorial do espaço Europeu, domínio em que, relembre-se, a CE não possui competência formal.

Apesar da forte institucionalização da Coesão Territorial enquanto objetivo político e princípio normativo a adotar na formulação de políticas públicas, bem como do crescente debate académico em torno do seu significado e da sua importância, ainda se verifica alguma nebulosidade no que respeita ao seu conceito e operacionalização. É certo que o Livro Verde sobre a Coesão Territorial (2008) e o processo de consulta pública sobre o mesmo procuraram clarificar esta questão, adicionando à visão inicial de combater disparidades territoriais e promover a equidade no acesso a Serviços de Interesse Geral (patente no lançamento formal do conceito no Tratado de Amesterdão em 1997), a perspetiva de valorizar a diversidade e complementaridades territoriais e facultar a possibilidade da população tirar o melhor partido das características 
existentes em cada território. Reconhecendo que só com esta visão conjunta será possível aspirar-se a um desenvolvimento harmonioso dos diferentes territórios do espaço europeu, acentua-se a necessidade de promover a articulação de diferentes políticas e atores no campo institucional. Mas não é menos verdade que as orientações apresentam-se, mesmo assim, demasiado abrangentes e pouco claras no que respeita à sua operacionalização. Esta questão tem igualmente sido debatida na arena académica (consultar, por exemplo, Faludi, 2007; 2010; Dühr et al, 2010; Servillo, 2010; Van Well, 2012) e é facilmente percetível do ponto de vista político (Eser, 2009, p. 20): “In politics there are (...) ways of making broad concepts of policies of a redistributive character (such as territorial cohesion) operational: One way is to have little concern about a clear definition and to leave things vague, as they are now, profiting from a sort of unifying unclearness. The vagueness allows for bargaining about political measures, covering the expectations of the various political stakeholders, and for declaring afterwards that all this is territorial cohesion. It would be for the researchers to ex-post make sense of, in our case, territorial cohesion as a coherent concept by trying to find the (un)intended storyline. The other extreme is, in terms of rationality, the ideal but in political terms the toughest way: First to clarify the concept and principles of territorial cohesion and then to develop indicators and policy measures with the help of research. The problem with this approach is that some stakeholders will not receive their expected benefit, which may provoke political resistance or the blocking of a discussion before it has even started".

Se do ponto de vista da criação de consenso político à escala europeia esta abrangência concetual pode ser percetível, já ao nível operacional a ideia de Coesão Territorial torna-se um alvo em movimento (Van Well, 2012), uma preocupação que tem vindo a emergir nos últimos anos, quer no seio de instituições europeias - por exemplo, o próprio Parlamento Europeu, na sua resolução sobre o Livro Verde (P6_TA(2009)0163), critica fortemente a não clarificação do conceito e ausência de uma tentativa de o operacionalizar -, quer em diversos países, cujas orientações, claramente influenciadas pela agenda da CE, apontam no sentido de se adotar este princípio na sua agenda política. Como refere Davoudi (2009, p. 271), “territorial cohesion is here to stay". 
De facto, esta influência (europeização) de princípios e orientações no âmbito de políticas decorrentes do processo de construção do espaço europeu tem marcado explícita ou implicitamente as políticas públicas nacionais e o próprio debate académico (Olsen, 2002; Featherstone e Radaelli, 2003; Ferrão, 2010). Já ao nível de políticas de base territorial, o facto do ordenamento do território não ser uma competência comunitária introduz uma menor exposição deste domínio aos mecanismos formais deste efeito europa dos "processos de decisão $e$, consequentemente, às adaptações ou transformações institucionais daí decorrentes" (Ferrão, 2010, p. 26). Neste caso, e seguindo Ferrão (2010), os mecanismos de difusão e de alteração de culturas e práticas advêm essencialmente da integração discursiva com recurso a um vocabulário comum, do desenho de visões espaciais partilhadas ou mesmo do desenvolvimento de práticas colaborativas transnacionais, envolvendo processos de aprendizagem mútua e promoção de boas práticas. O exemplo mais divulgado neste contexto consiste no processo de elaboração do EDEC - Esquema de Desenvolvimento de Espaço Comunitário (CEC, 1999), um referencial estratégico para o desenvolvimento do espaço europeu com uma influência significativa nas opções e prioridades tomadas pelos Estados-Membros (Ferrão, 2004). No caso específico de Portugal, o efeito EDEC é visível em diversos elementos de referência, influência que serviu inclusive como palco de discussão académica (consultar, por exemplo, Ferrão, 2004; Mourato e Pires, 2007).

No período mais recente, é possível encontrar outros mecanismos de difusão que têm procurado contribuir para socializar a agenda discursiva de âmbito europeu e mobilizar os Estados-Membros em torno destas questões. Destacam-se, aqui, a Agenda Territorial (CEC, 2007), posteriormente reformulada (CEC, 2011), e o já mencionado Livro Verde sobre a Coesão Territorial (2008), tendo como ponto comum a tentativa de centrar o debate em torno da Coesão Territorial e o sublinhar da importância da inclusão deste objetivo político europeu nas orientações nacionais.

Neste contexto, importa sublinhar o caso húngaro como um bom exemplo no que respeita a este fenómeno de europeização e ao esforço de clarificar os processos de formulação de políticas públicas tendo por base a Coesão Territorial, publicando um documento sobre a sua integração na agenda nacional (consultar Botka, 2009) e, na 
sequência deste, um outro documento para a implementação nacional da Agenda Territorial da UE (tendo por base a Coesão Territorial) (consultar Ricz, 2010). No entanto, trata-se de um caso isolado e muito possivelmente justificado pelo facto do lançamento destes documentos ter surgido durante o período em que a Hungria se encontrava na presidência da UE e, portanto, com este dossier em mãos. Consequentemente, e como refere Van Well (2012, p. 1550), "Despite the recent degree of institutionalization and the growing body of solid policy-relevant studies on the topic, territorial cohesion remains essentially a moving target and each EU Member State and region conceptualizes the policy goal in Cohesion Policy instruments as befits the specific regional challenges and opportunities of the territory".

Nos próximos pontos aprofundar-se-á esta questão da transição do princípio de Coesão Territorial da agenda política da CE para os Estados-Membros, com particular enfase no caso português.

\section{A integração do princípio de Coesão Territorial na agenda política portuguesa: contexto e considerações metodológicas}

A análise de como o princípio de Coesão Territorial está e/ou pode ser interpretado nos diferentes Estados-Membros tem sido recentemente palco de alguma discussão académica e política. Parte do debate tem incidido essencialmente na influência que as diferentes tradições de planeamento do território ao nível Europeu produzem na apropriação de determinados conceitos e práticas. Destacam-se, aqui, os trabalhos desenvolvidos por Janin-Rivolin e Faludi (2005), chamando a atenção para a necessidade de se articularem as diferentes conceções de Coesão Territorial com as diversas tipologias de sistemas de planeamento do território, Knieling e Othengrafen (2009), focando-se na influência que as diferentes culturas de planeamento territorial produzem na incorporação de determinados conceitos, Faludi (2007) e Davoudi e Strange (2009), debruçando-se sobre o Modelo Social Europeu e a sua relação com a Coesão Territorial, Cotella e Janin-Rivolin (2010), associando à noção de Coesão Territorial a ideia de governança territorial enquanto processo de interação do 
planeamento territorial com outras atividades e políticas comunitárias, e Colomb e Santinha (2012), refletindo sobre os desafios decorrentes da forte tendência de liberalização dos Serviços de Interesse Geral na promoção da Coesão Territorial. Num outro registo, encontra-se o trabalho desenvolvido por Sykes (2011), procurando compreender como o conceito de Coesão Territorial está a ser interpretado no Reino Unido à luz das respostas dadas por diversos atores no âmbito da discussão do Livro Verde sobre Coesão Territorial. A opção tomada por Sykes em deixar de lado as respostas fornecidas pelo governo britânico e outros instrumentos políticos reside no facto de o próprio governo argumentar que o significado de Coesão Territorial já está clarificado em diversos documentos europeus, designadamente o Livro Verde, demitindo-se, por isso mesmo, de o aprofundar e de lançar orientações nesse sentido. Por seu turno, Luukkonen e Moilanen (2012), debruçando-se sobre a ideia de soft planning, realçam a importância dos processos colaborativos em novas formas de conceber o território para alcançar a Coesão Territorial, utilizando como estudo de caso a Ostrobótnia (Bothnian Arc) para aferir a diferença entre a retórica política e a sua operacionalização. Por fim, Van Well (2012) procura mostrar as diferentes interpretações existentes analisando inúmeros documentos de orientação política, que criam o que o autor designa por meta-storylines. Partindo de um estudo prévio elaborado pela Nordregio (2009), a autora compara as orientações comunitárias (lógica top-down nas palavras da autora) com as provenientes de 246 Programas Operacionais do programa de financiamento comunitário 2007/13 (lógica bottom-up).

A investigação aqui apresentada procura colmatar a ausência de trabalhos produzidos sobre esta temática em Portugal e contribuir para uma maior discussão sobre como a transição do conceito está a ser efetuada para os Estados-Membros, aqui exemplificada com o caso português. Face à ausência de documentação específica sobre o princípio de Coesão Territorial na formulação de políticas públicas em Portugal, a opção metodológica consistiu na análise dos principais instrumentos de orientação estratégica, tentando aferir-se se e como este princípio começa a fazer parte das orientações nacionais de política pública. Por isso mesmo, a abordagem compreendeu a procura de registos explícitos do termo Coesão Territorial e a observação da forma como é interpretado, seja à luz de definições que os próprios 
instrumentos avancem, seja através da forma como o termo é contextualizado nos documentos. Por se verificar, na maioria dos casos, uma alusão pouco explícita do conceito, a análise contextual foi bastante útil para aferir, ainda que implicitamente, como a ideia de Coesão Territorial foi interpretada nesses instrumentos.

No que respeita aos instrumentos integrantes do Sistema de Planeamento, foram analisados aqueles de natureza estratégica que traduzem as grandes opções para o ordenamento do território, designadamente o Programa Nacional da Política de Ordenamento do Território (PNPOT, 2007) e os diversos Planos Regionais de Ordenamento do Território (PROT), concluídos - PROT Algarve (2007), PROT OVT (2009) e PROT Alentejo (2010) - ou ainda em fase de pós-discussão pública - PROT AML, PROT Centro e PROT Norte. Por outro lado, existem outros instrumentos de orientação estratégica que, não integrando os designados Instrumentos de Gestão Territorial, produzem impactos no território, pelo que a sua análise também se revela fundamental para a compreensão do fenómeno em causa. Integram este grupo o Quadro de Referência Estratégico Nacional (QREN 2007/2013), o Programa Nacional de Acção para o Crescimento e o Emprego (PNACE 2005/08), a Estratégia Nacional de Desenvolvimento Sustentável (ENDS 2015), o Plano Estratégico Nacional de Desenvolvimento Rural (PENDR 2007/13) e a Política de Cidades POLIS XXI (2007/13). Refira-se que estes instrumentos têm a particularidade de se mencionarem de forma cruzada, o que representa um estímulo adicional para a aferição da existência de linhas de orientação comuns. Por fim, efetuou-se também uma análise do Contributo das Autoridades Portuguesas para a consulta pública sobre o Livro Verde (MNE, 2008) que, não sendo um instrumento de orientação estratégica, é útil compreender a sua diretriz, na medida em que representa a 'voz' formal do Governo Português e, supostamente, uma visão conjunta do conceito de Coesão Territorial.

Na próxima secção apresenta-se um resumo dos principais pontos que decorrem da análise individual destes instrumentos, ponto de partida para o ponto seguinte no qual se faz uma análise conjunta da forma como estes instrumentos adotam o conceito de Coesão Territorial, o que por sua vez é ilustrador da forma como o conceito está a ser interpretado e introduzido na agenda política portuguesa. 


\section{4. (des)mistificando a adoção do princípio de Coesão Territorial na agenda política portuguesa: a dimensão analítica}

O ponto de partida da análise consiste na leitura e interpretação dos Instrumentos de Gestão Territorial acima referidos: PNPOT e PROT.

No que respeita o PNPOT, a preocupação subjacente à noção de Coesão Territorial é observada explícita e implicitamente em vários momentos do programa:

- "A promoção da coesão territorial pressupõe a capacidade de as cidades dinamizarem processos de desenvolvimento regional e assegurarem o acesso generalizado a Serviços de Interesse Geral, incluindo os serviços económicos. Por outro lado, a eficiência das intervenções de desenvolvimento regional depende da forma como as diversas ações se reforcem mutuamente, o que implica a concentração de intervenções tomando a rede de cidades como referência" (PNPOT, 2007, p. 38);

- "As infraestruturas e redes de transportes assumem um papel chave da acessibilidade e mobilidade inter e intra-regional e, portanto, como impulsionadores da coesão, integração e ordenamento territorial do país" (PNPOT, 2007, p. 39);

- "O sistema infraestrutural de suporte das acessibilidades constitui também um dos pilares fundamentais do modelo territorial policêntrico que se visa promover" (PNPOT, 2007, p. 39);

- "No desenvolvimento dos sistemas de transportes e para assegurar a eficiência das deslocações assume especial relevância a boa articulação e integração entre redes de diferentes níveis hierárquicos e modos de transporte, especialmente nas parcelas do território com menor densidade de ocupação" (PNPOT, 2007, p. 39);

- "A prestação de serviços públicos através do recurso às TIC é igualmente uma vertente essencial para consolidar a sociedade de informação e promover a coesão social e territorial" (PNPOT, 2007, p. 55). Sobre esta questão o PNPOT 
refere ainda o seguinte: "Alargar a gama de oferta de serviços colectivos e de interesse público suportados na Internet e na utilização das TIC, por exemplo nos domínios da saúde ou da educação, garantindo o seu acesso nos espaços de baixa densidade" (PNPOT, 2007, p. 39);

- "Assegurar a equidade territorial no provimento de infraestruturas e de equipamentos colectivos e a universalidade no acesso aos serviços de interesse geral, promovendo a coesão social"' (PNPOT, 2007, p. 42).

Refira-se, no entanto, que não é clara a definição de Coesão Territorial ou, dito de um outro modo, fica por esclarecer o significado e o que implica fazer para se obter um território mais coeso. Apesar de tudo, poderá argumentar-se que a noção de Coesão Territorial vem associada à ideia de acesso generalizado a Serviços de Interesse Geral, desenvolvimento de infraestruturas e redes de transportes (ou seja, acessibilidade e mobilidade), utilização de tecnologias de informação e comunicação, aposta num modelo territorial policêntrico e desenvolvimento de redes.

Ocupando uma posição de charneira fundamental no Sistema de Gestão Territorial nacional, e em articulação estreita com o PNPOT, encontram-se os PROT. No documento de orientação publicado em Novembro de 2005 pela SEOTC é possível encontrar referências ao princípio de Coesão Territorial (ainda que, mais uma vez, esteja pouco explícito do ponto de vista concetual). Procurando dar seguimento à 3 a opção das GOP 2005-2009 - melhorar a qualidade de vida e reforçar a coesão territorial num quadro sustentável de desenvolvimento -, o PROT surge como um instrumento relevante e oportuno para definir uma estratégia de Coesão Territorial: “Face a este contexto, a elaboração dos PROT através de um processo alargado a todas as regiões e promovido pelas Comissões de Coordenação e Desenvolvimento Regional, é uma prioridade, sendo uma peça fundamental do sistema de integração e coesão territorial que está na base de qualquer processo de desenvolvimento regional" (SEOTC, 2005, p. 4). No mesmo documento, e embora não sendo explicitamente referido o princípio de Coesão Territorial, é ainda mencionado que os PROT devem respeitar diversos fatores que, de certa forma, procuram contribuir para um território mais coeso: "diversidade regional (definição de unidades territoriais de âmbito subregional), integração regional (articulação com outras regiões, nomeadamente regiões 
vizinhas), integração sectorial territorial (articulação das políticas com incidência territorial), sustentabilidade dos processos de desenvolvimento (conciliar sustentabilidade ambiental, competitividade económica e equidade de oportunidades)" (SEOTC, 2005, p. 6).

Uma leitura dos vários PROT entretanto aprovados (ou em fase de discussão pública) permite afirmar que estes instrumentos, pelo menos do ponto de vista discursivo nos relatórios elaborados, fazem diversas referências ao princípio de Coesão Territorial, na globalidade em muito associado à perspetiva de diversidade e valorização territorial, promoção de um modelo territorial baseado numa organização policêntrica, valorização das potencialidades endógenas, desenvolvimento das áreas mais desfavorecidas e equidade no acesso a bens e serviços. O Quadro 1 procura apresentar uma síntese das principais observações efetuadas em cada plano sobre Coesão Territorial.

Quadro 1 - Sistematização das principais considerações efetuadas nos PROT sobre Coesão Territorial

\begin{tabular}{|l|l|}
\hline PROT & $\begin{array}{l}\text { Principais considerações subjacentes ao princípio de Coesão } \\
\text { Territorial }\end{array}$ \\
\hline (2007) & $\begin{array}{l}\text { - Ulgarve dos objetivos estratégicos consiste em promover um modelo } \\
\text { territorial equilibrado e competitivo, contendo a pressão urbanística } \\
\text { sobre o litoral e aumentando o potencial de desenvolvimento das } \\
\text { áreas deprimidas do interior, assegurando a coesão territorial e o } \\
\text { aproveitamento integrado das potencialidades dos diversos territórios } \\
\text { (p. 24) } \\
\text { - Uma das sete opções estratégicas visa o reequilibrio territorial, na } \\
\text { qual se refletem objetivos de coesão territorial e de fomento do } \\
\text { desenvolvimento das áreas mais desfavorecidas do interior da região } \\
\text { (p.27) }\end{array}$ \\
\hline PROT-OVT (2009) & $\begin{array}{l}\text { - Na medida em que este PROT é desenhado numa ótica de forte } \\
\text { articulação com outros instrumentos de desenvolvimento territorial, } \\
\text { este instrumento apresenta-se relevante e oportuno para } \\
\text { conceptualizar e implementar uma estratégia de coesão territorial } \\
\text { para a Região do Oeste e Vale do Tejo (p. 12). } \\
\text { - No eixo estratégico 2 (Potenciar as Vocações Territoriais num } \\
\text { Quadro de Sustentabilidade Ambiental) consta o seguinte objetivo: } \\
\text { Proteger e valorizar os recursos naturais, patrimoniais e culturais } \\
\text { através de medidas que os integrem na gestão do planeamento } \\
\text { territorial regional e municipal, numa perspectiva de coesão territorial } \\
\text { e reforço da identidade regional (p. 46) } \\
\text { - No modelo territorial proposto avança-se com a ideia de que no } \\
\text { sistema urbano os centros urbanos devem organizar-se segundo uma }\end{array}$ \\
\hline
\end{tabular}




\begin{tabular}{|c|c|}
\hline & $\begin{array}{l}\text { tipologia de centros assente na diversidade funcional, para o qual a } \\
\text { aposta em centros complementares é fundamental na sustentação da } \\
\text { coesão territorial e na consolidação de redes de proximidade. Por sua } \\
\text { vez, estas redes capacitam os centros urbanos para novos e mais } \\
\text { exigentes desafios em termos de competitividade, e garantem uma } \\
\text { oferta de serviços complementares essenciais para valorização da } \\
\text { qualidade de vida residencial (p. 56-57) }\end{array}$ \\
\hline $\begin{array}{l}\text { PROT-Centro } \\
\text { (2010) }\end{array}$ & $\begin{array}{l}\text { - À semelhança do PROT - OVT, também aqui é feita a associação do } \\
\text { princípio de coesão territorial aos centros urbanos complementares: } \\
\text { Os centros urbanos complementares têm uma função } \\
\text { dominantemente municipal, garantindo uma oferta urbana essencial } \\
\text { para a coesão territorial (p. 52) } \\
\text { - Ainda no âmbito dos sistemas urbanos é referido que é fundamental } \\
\text { contribuir para a melhoria da equidade na distribuição de serviços, e } \\
\text { desta forma reforçar a coesão territorial (pág. 53). Assim, Políticas } \\
\text { sectoriais de saúde, educação e formação, apoio social, cultura e } \\
\text { património cultural, desporto e lazer [devem ser] compatíveis com a } \\
\text { territorialização do modelo de ordenamento e de desenvolvimento } \\
\text { para a Região. Do mesmo modo, deve ser definido um sistema urbano } \\
\text { regional que oriente a definição e estruturação das redes de serviços, } \\
\text { infraestruturas e equipamentos públicos de âmbito supra-municipal e } \\
\text { regional, garantindo condições de equidade territorial em termos de } \\
\text { cobertura e acessibilidade (p. 91) } \\
\text { - Verifica-se, implicitamente, uma relação entre o princípio de coesão } \\
\text { territorial evocado pelo PROT - Centro e o desenvolvimento } \\
\text { policêntrico e a promoção da relação urbano/rural. }\end{array}$ \\
\hline $\begin{array}{l}\text { PROT - Alentejo } \\
\text { (2010) }\end{array}$ & $\begin{array}{l}\text { - Como grande desígnio, o PROTA pretende afirmar o Alentejo como } \\
\text { território sustentável e de forte identidade regional, sustentada por } \\
\text { um sistema urbano policêntrico, garantindo adequados níveis de } \\
\text { coesão territorial e integração reforçada com outros espaços } \\
\text { nacionais e internacionais, valorizando o seu posicionamento } \\
\text { geoestratégico (RCM n.o 53/2010:2962), considerando o Garantir } \\
\text { níveis adequados de coesão territorial como um dos nove desafios } \\
\text { que se colocam ao ordenamento do território da região. } \\
\text { - Ao nível do sistema urbano relaciona o do princípio de coesão } \\
\text { territorial com os centros urbanos complementares, mencionando } \\
\text { igualmente que o modelo de organização do sistema urbano deve } \\
\text { assentar na opção de uma organização policêntrica, quer ao nível } \\
\text { regional, assente no reforço de redes de concertação estratégica, quer } \\
\text { ao nível dos subsistemas sub-regionais, tomando-o como a estrutura } \\
\text { fundamental de suporte à coesão territorial e ao desenvolvimento } \\
\text { sub-regional (RCM n.o 53/2010:2970). Ainda no âmbito deste } \\
\text { argumento, considera enquanto objetivos estratégicos, quer } \\
\text { Estruturar redes de centros urbanos sub-regionais assentes na } \\
\text { concertação intermunicipal de recursos e equipamentos, capazes de } \\
\text { sustentar a coesão territorial e de garantir o acesso a serviços } \\
\text { colectivos e funções urbanas de gama alargada, quer Promover o } \\
\text { acesso às redes e ao uso das TIC, nomeadamente por parte das } \\
\text { empresas e dos serviços públicos, contribuindo para um }\end{array}$ \\
\hline
\end{tabular}




\begin{tabular}{|c|c|}
\hline & $\begin{array}{l}\text { desenvolvimento mais integrado e uma maior coesão territorial (RCM } \\
\text { n.- 53/2010:2981) } \\
\text { - É feita ainda uma forte ligação entre a coesão territorial e as áreas } \\
\text { rurais: A estratégia de revitalização económica e social das zonas } \\
\text { rurais deverá ser concretizada através de objectivos específicos, tais } \\
\text { como: implementação de serviços de proximidade; dinamização e } \\
\text { diversificação da atividade económica e do emprego em meio rural; } \\
\text { desenvolvimento de competências nas zonas rurais e promoção do } \\
\text { reforço da coesão territorial e social (RCM n.o 53/2010:2979) } \\
\text { - Importa, por fim, destacar que a cooperação institucional é ainda } \\
\text { vista como meio essencial para a coesão territorial: A consolidação de } \\
\text { um sistema urbano policêntrico de suporte à coesão territorial assenta } \\
\text { num conjunto de subsistemas urbanos regionais e em eixos urbanos } \\
\text { de proximidade, sustentados em mobilidade, em parcerias de âmbito } \\
\text { urbano -rural e ou em cooperações estratégicas interurbanas (RCM n.o } \\
53 / 2010: 3002 \text { ) }\end{array}$ \\
\hline $\begin{array}{l}\text { PROT - Norte } \\
\text { (2010) }\end{array}$ & $\begin{array}{l}\text { - É afirmado aqui que o ordenamento do território, ao procurar as } \\
\text { formas de organização espacial que optimizem a sua ocupação e } \\
\text { utilização numa perspectiva de sustentabilidade, tem forçosamente de } \\
\text { incorporar, independentemente de outras fundamentações, o reforço } \\
\text { da coesão territorial como um dos seus objectivos próprios. E neste } \\
\text { sentido considera os seguintes benefícios decorrentes do reforço da } \\
\text { Coesão Territorial: Contribuir para uma maior equidade nas condições } \\
\text { de vida das populações e Potenciar os factores territoriais que } \\
\text { contribuem positivamente para as dinâmicas de desenvolvimento. } \\
\text { Acrescentando, em seguida, que Por esta via, as políticas de } \\
\text { ordenamento territorial, e os instrumentos que as materializam, } \\
\text { deverão desejavelmente incluir a temática da coesão territorial no } \\
\text { corpo central das suas preocupações e objectivos (p. 19) } \\
\text { - A promoção da Coesão Territorial é assim vista como complemento } \\
\text { optimizador da competitividade territorial, materializada pela } \\
\text { crescente equidade territorial de acesso a bens, serviços e } \\
\text { oportunidades que, por sua vez, deverá ser garantida através da } \\
\text { máxima eficiência das intervenções - em termos de rapidez de efeitos } \\
\text { e de universalização - num contexto de utilização sustentável dos } \\
\text { recursos. (...) Tal fundamenta e legitima a adopção de elementos de } \\
\text { descriminação positiva nas políticas e ações a empreender, uma vez } \\
\text { que a manutenção de níveis mínimos de coesão territorial pode exigir } \\
\text { a existência permanente de serviços / equipamentos mínimos, não } \\
\text { sustentados em critérios ou limiares económicos para as procuras } \\
\text { existentes ou potenciais (p. 24) }\end{array}$ \\
\hline PROT - AML (2010) & $\begin{array}{l}\text { Na visão deste PROT para } 2020 \text { começa por fazer-se uma referência } \\
\text { explícita à Coesão Territorial nos seguintes moldes: A sustentabilidade } \\
\text { social e ambiental, o reforço da coesão sócioterritorial, a valorização } \\
\text { da diversidade étnica e cultural, a competitividade internacional e a } \\
\text { eficiência da governação são, nesse horizonte, condições e metas do } \\
\text { desenvolvimento económico e social da Região (p. 25). } \\
\text { - Contudo, a noção de Coesão Territorial é pouco explorada }\end{array}$ \\
\hline
\end{tabular}




\begin{tabular}{|l|l|}
\hline & explicitamente neste plano e, quando surge, é associada \\
particularmente à ideia de coesão social e cultural. Por isso mesmo, a \\
menção explícita é efetuada nos domínios de intervenção que dizem \\
respeito à Equidade no Acesso e Participação nas Atividades Culturais \\
e do Conhecimento (p. 269). \\
- É também possível encontrar o termo coesão em que a dimensão \\
territorial está presente, ainda que não de forma explícita, mas que \\
ajuda a perceber a interpretação dada pelos autores a este conceito: \\
O sistema urbano fundamental deve estruturar-se e sustentar-se em \\
torno de quatro níveis de aglomerações urbanas, cuja coesão, massa \\
crítica e capacidade polarizadora resultam da agregação de \\
centralidades próximas e com significativa interdependência (p. 92). \\
As noções de massa crítica e policentrismo emergem, assim, \\
facilmente a partir desta visão de coesão para o sistema urbano.
\end{tabular}

Refira-se que no próprio documento de orientação dos PROT é igualmente mencionada a importância de um outro instrumento de orientação política, o QREN 2007/2013, "no qual se integram as opções estratégicas de desenvolvimento que as Regiões definirem para os próximos anos. Esta dinâmica não só é especialmente favorável ao lançamento de uma reflexão sobre a organização territorial da Região e sobre o uso e a transformação do território a consubstanciar no PROT, como necessita da incorporação das políticas territoriais para garantir a sustentabilidade da trajetória de desenvolvimento pretendida. Como tal, os PROT, além de serem um pilar da política de desenvolvimento territorial, são documentos fundamentais para a definição dos programas de ação a integrar no próximo período de programação das intervenções co-financiadas pelos Fundos Estruturais e de Coesão da União Europeia" (SEOTC, 2005, p. 3).

Tendo por base as orientações da Política de Coesão da UE, O QREN 2007/2013 menciona também a Coesão Territorial enquanto objetivo a alcançar, designadamente através das orientações que emana para os respetivos Programas Operacionais. Aliás, no diagnóstico efetuado à situação portuguesa e exposto no documento do QREN 2007/2013, é destinada uma secção à Coesão Territorial, associando-se, de uma forma generalizada, o objetivo de coesão à procura de convergência em matéria de condições e qualidade de vida: "com um interior menos estigmatizado" (p. 33).

A mesma observação pode ser feita em relação ao PNACE 2005/2008: elaborado sensivelmente no mesmo período, e tendo como referência a Estratégia de Lisboa, considera a Coesão Territorial uma política transversal integrante da estratégia de 
desenvolvimento que preconiza, referindo inclusive que "a próxima geração de política regional contemplará medidas de discriminação positiva a favor de regiões menos desenvolvidas no caso de projetos com elevado potencial inovador $e$ indutores de progresso tecnológico" (PNACE, 2005, p. 25). Numa secção destinada à Coesão Territorial (e sustentabilidade ambiental), e embora sem nunca explicitar o seu significado ou o caminho para a alcançar, encontram-se associadas expressões como 'valorização do território', 'coerência e eficiência dos instrumentos de ordenamento', 'sistema urbano mais policêntrico' e 'redes de cooperação'.

Importa também mencionar que o próprio PNACE 2005/2008 destaca a Política de Cidades POLIS XXI enquanto instrumento de orientação política que reforça a capacidade de inovação, a competitividade e a internacionalização da base económica com a melhoria da qualidade de vida, cujo financiamento dos instrumentos que utiliza está assegurado através dos Programas Operacionais do QREN 2007-2013. Partindo do reconhecimento que "um modelo de desenvolvimento cada vez mais dependente do conhecimento e da inovação pressupõe uma sólida base urbana e exige às cidades uma elevada qualificação das suas funções e uma forte capacidade de fixação e atração de pessoas criativas e de atividades inovadoras" (POLIS XXI, 2008, p. 3), esta política tem como referencial o modelo territorial consagrado no PNPOT e, como tal, deve contribuir para a coesão territorial - mencionando, por isso mesmo, a necessidade de reforçar espaços do interior e privilegiar ligações em rede.

Por outro lado, e porque o território não compreende só espaços urbanos (aliás, a própria Política de Cidades POLIS XXI sublinha a necessidade de se promoverem relações de complementaridade entre espaços urbanos e rurais), convém dizer que o PENDR 2007/2013 refere que um modelo de desenvolvimento rural sustentável implica o reforço da coesão territorial (e social), fator fundamental do desenvolvimento nacional, impossível de concretizar em toda a sua extensão sem que seja assegurada a diminuição das disparidades territoriais.

Por fim, concebida como um mecanismo de integração e projeção no horizonte de 2015 dos diversos instrumentos de orientação estratégica nacional, designadamente do PNPOT e do PNACE, importa referir a ENDS - 2015. O grande desígnio que enforma este instrumento de orientação estratégica é o de "Retomar uma trajetória de 
crescimento sustentado que torne Portugal, no horizonte de 2015, num dos países mais competitivos e atrativos da União Europeia, num quadro de elevado nível de desenvolvimento económico, social e ambiental e de responsabilidade social" (ENDS, 2008, p. 12). Para alcançar tal desígnio são traçados diversos objetivos, destacando-se para os devidos efeitos o quinto: Melhor conectividade internacional do país $e$ valorização equilibrada do território (ENDS, 2008, p. 44). Neste, é sublinhado que deverão ser "mobilizados os diversos instrumentos de planeamento com impacto direto no território, aproveitando e valorizando os diferentes recursos naturais e as diversas potencialidades e atividades locais e regionais, de modo a favorecer um modelo de desenvolvimento mais sustentável no plano económico e social e mais coerente e equilibrado em termos ambientais e territoriais", sendo feita referência explícita à promoção do policentrismo urbano e da Coesão Territorial enquanto orientações estratégicas a assumir perante a evolução da organização territorial no horizonte temporal da ENDS - 2015. Neste âmbito, as ideias subjacentes ao conceito de Coesão Territorial consistem essencialmente em: articular a estrutura do sistema urbano com a das redes de transportes e acessibilidades, reforçar o desenvolvimento policêntrico enquanto fator orientador do ordenamento do conjunto da estrutura urbana e do sistema de acessibilidades, integrar como parceiros ativos os territórios de baixa densidade nas dinâmicas de desenvolvimento, promover uma perspetiva integrada de desenvolvimento urbano-rural e, ainda, assegurar uma boa conectividade digital da malha policêntrica referida e promover o enraizamento local das competências em tecnologias de informação e comunicação.

Importa ainda referir que a ENDS faz igualmente referência ao facto da sustentabilidade de desenvolvimento passar por uma administração pública mais eficiente e modernizada (sétimo objetivo) que, entre outras questões, não só seja capaz de "ultrapassar um funcionamento muito fragmentado e centrado na visão setorializada, para um funcionamento em rede, privilegiando a cooperação, as parcerias e a participação, nomeadamente dos atores socioeconómicos e dos cidadãos em geral, que garanta resposta à necessidade de definir e implementar políticas cada vez mais transversais e integradoras de múltiplas valências e responsabilidades, como também esteja dotada de sectores de provisão de bens e serviços públicos, 
designadamente um sistema de justiça mais ágil e moderno, contribuindo positivamente para o reforço da confiança e para a regulação económica e social, $e$ sistemas de educação, saúde e segurança mais eficientes e com maior qualidade" (ENDS, 2008, p. 51). Ora, embora neste objetivo em concreto não se faça qualquer menção explícita à Coesão Territorial, a noção de articulação de atores, políticas e instituições relaciona-se com a ideia de Coesão Territorial como se constatou na segunda secção deste texto.

À observação dos principais documentos de orientação estratégica segue-se a análise do contributo formal (e institucionalmente transversal) das Autoridades Portuguesas para a consulta pública sobre o Livro Verde. Sendo um documento direcionado para a Coesão Territorial, ao contrário dos documentos analisados anteriormente, é natural que o grau de profundidade sobre o conceito de Coesão Territorial seja diferente. No entanto, mais do que se discutir uma perspetiva operacional de Coesão Territorial, no documento fica espelhada a preocupação em clarificar-se o porquê e o para quê da sua adoção política. Do ponto de vista conceptual, a ideia de Coesão Territorial fica associada a questões como "maior coerência entre diferentes políticas" (MNE, 2008, p. 6), "maior convergência e integração entre distintos territórios" (MNE, 2008, p. 6) e valorização das "especificidades territoriais" (MNE, 2008, p. 9). Não se verifica, portanto, uma explicitação clara do que significa um território coeso e quais os caminhos a trilhar para se alcançar a Coesão Territorial.

Efetuada a análise deste contributo governamental, bem como dos principais instrumentos de orientação estratégica, sobre se e como o princípio de Coesão Territorial é abordado, importa agora fazer uma leitura global dos mesmos sobre a interpretação dada ao conceito. 


\section{5. (des)mistificando a adoção do princípio de Coesão Territorial na agenda política portuguesa: a dimensão interpretativa}

A análise da adoção do princípio de Coesão Territorial nos instrumentos supracitados pode ser efetuada à luz de três registos complementares: o período de preparação e publicação dos documentos de suporte dos instrumentos (anterior vs posterior ao Livro Verde), a natureza da adoção do conceito (orientação estratégica vs objetivo explícito) e as ideias-chave (dimensões analíticas) que caraterizam a forma como o conceito é interpretado nesses mesmos instrumentos.

Os documentos analisados foram publicados entre 2005 e 2010, incluídos no período pós lançamento do Livro Verde sobre a Coesão Territorial (2008) apenas alguns dos PROT. Tal significa que, na maior parte dos casos, a publicação do Livro Verde e o respetivo período posterior de discussão pública acabaram por não influenciar diretamente a elaboração destes documentos. É verdade que a ideia de Coesão Territorial surge bastante antes no seio das políticas da $C E$, como já referido. $E$, por isso, seria expectável a sua referência independentemente do Livro Verde. Mas não é menos certo que a existência deste documento e de um período de debate público transnacional vieram atribuir um valor acrescentado adicional para a sua adoção nas agendas nacionais e um maior potencial de esclarecimento do seu significado. Contudo, a análise efetuada mostra que o grau de profundidade e de explicitação do conceito é independente do lançamento do Livro Verde. Duas razões podem, desde logo, ser apontadas. Por um lado, que o processo de elaboração dos referidos PROT começou antes do lançamento do Livro Verde, pairando a dúvida se este poderia, de facto, ter exercido alguma influência direta. Por outro lado, que o Livro Verde e a sua discussão pública tiveram pouca repercussão em Portugal, não sensibilizando, por isso, os atores nacionais para a necessidade de incorporarem a ideia de Coesão Territorial de forma mais explícita e esclarecedora.

A natureza da adoção do conceito pode também auxiliar a compreender qual a ambição e centralidade que estes instrumentos lhe conferem. Neste contexto, é 
possível encontrar a Coesão Territorial, quer como orientação estratégica, quer como objetivo específico. Enquanto orientação estratégica o conceito ganha outra aspiração e centralidade e passa a servir como referência para a formulação de determinados objetivos específicos. São exemplos disso, o QREN 2007/13, o PNACE 2005/2008 ou mesmo a Política de Cidades POLIS XXI. Enquanto objetivo específico, o conceito, não só perde protagonismo, como passa a ser considerado um fim em si. Encontram-se aqui incluídos alguns dos PROT, como sejam o PROT Alentejo e o PROT Norte. No entanto, esta distinção nem sempre é passível de se efetuar com precisão, dada a ambiguidade com que o conceito é considerado nos instrumentos e a forma em que é usado, verificando-se em diversas situações a dupla natureza.

Por fim, importa sumariar e comentar as ideias-chave que decorrem da análise de conteúdo efetuada no ponto anterior e que permite aferir como a Coesão Territorial foi interpretada no processo de elaboração dos instrumentos em causa (Quadro 2).

O facto de, por diversas vezes, ser feita referência, neste mesmos documentos, a outros instrumentos orientadores e sublinhada a importância destes se articularem, uma leitura mais aprofundada dos mesmos (e refletida no quadro síntese anterior) confirma que as orientações não convergem totalmente no que respeita ao significado que é conferido à Coesão Territorial. Aliás, a própria abrangência com que o conceito é adotado no âmbito do contributo formal das Autoridades Portuguesas para a consulta pública sobre o Livro Verde e a necessidade sentida em debruçar-se essencialmente na explicação da razão de ser da sua adoção política espelham bem a dificuldade em definir-se e seguir-se um rumo comum para a operacionalização do princípio de Coesão Territorial. Este contexto - formas diferenciadas de considerar o conceito na agenda política e sua amplitude interpretativa - indica bem a heterogeneidade e o carácter multidimensional deste princípio. 
Quadro 2 - Sistematização da leitura dos documentos de orientação estratégica no que respeita às principais ideias associadas à Coesão Territorial

\begin{tabular}{|c|c|}
\hline $\begin{array}{l}\text { Documento de orientação } \\
\text { estratégica }\end{array}$ & Principais ideias associadas à Coesão Territorial \\
\hline PNPOT & $\begin{array}{l}\text { - Dinamização de processos de desenvolvimento regional } \\
\text { (concentração de intervenções tomando a rede de cidades } \\
\text { como referência e o modelo de desenvolvimento policêntrico) } \\
\text { - Acesso generalizado a Serviços de Interesse Geral } \\
\text { - Desenvolvimento de infraestruturas e redes de transportes }\end{array}$ \\
\hline PROT & $\begin{array}{l}\text { - Aposta em modelos de organização territorial baseados num } \\
\text { sistema urbano policêntrico, em serviços de proximidade e na } \\
\text { dinamização e diversificação da atividade económica e do } \\
\text { emprego em meio rural } \\
\text { - Valorização da diversidade territorial e promoção de } \\
\text { potencialidades endógenas } \\
\text { - Promoção de equidade no acesso a bens, serviços e } \\
\text { oportunidades (adoção de elementos de discriminação } \\
\text { positiva) } \\
\text { - Cooperação institucional e articulação de políticas }\end{array}$ \\
\hline QREN 2007/2013 & $\begin{array}{l}\text { - Convergência em matéria de condições e qualidade de vida } \\
\text { - Reforço das redes de estruturação do território } \\
\text { (conectividade nacional e internacional) }\end{array}$ \\
\hline PNACE 2005/2008 & $\begin{array}{l}\text { - Valorização equilibrada do território (medidas de } \\
\text { discriminação positiva a favor de regiões menos } \\
\text { desenvolvidas, sistema urbano mais policêntrico, redes de } \\
\text { cooperação) } \\
\text { - Valorização das potencialidades endógenas } \\
\text { - Articulação de políticas e instrumentos de ordenamento }\end{array}$ \\
\hline $\begin{array}{l}\text { Política de Cidades POLIS } \\
\text { XXI }\end{array}$ & $\begin{array}{l}\text { - Reforço dos espaços do interior (relações de } \\
\text { complementaridade entre espaços urbanos e rurais) } \\
\text { - Promoção de ligações em rede }\end{array}$ \\
\hline ENDR 2007/2013 & - Diminuição das assimetrias regionais \\
\hline ENDS 2015 & $\begin{array}{l}\text { - Valorização equilibrada do território (acessibilidades, } \\
\text { desenvolvimento policêntrico, desenvolvimento urbano-rural, } \\
\text { conectividade digital) } \\
\text { - Promoção de administração pública mais eficiente e } \\
\text { modernizada (funcionamento em rede, participação, políticas } \\
\text { transversais, bens e serviços públicos) }\end{array}$ \\
\hline $\begin{array}{l}\text { Contributo das Autoridades } \\
\text { Portuguesas }\end{array}$ & $\begin{array}{l}\text { - Articulação de políticas e atores de diferentes territórios } \\
\text { - Valorização das especificidades territoriais }\end{array}$ \\
\hline
\end{tabular}


$\mathrm{Na}$ verdade, os dois registos anteriores - período de preparação e publicação dos documentos e natureza da adoção do conceito - poderiam conferir algum sentido a esta heterogeneidade, mas as conclusões alcançadas através da leitura documental não permitem efetuar qualquer observação adicional. Apesar de tudo, é possível identificar três dimensões analíticas que caraterizam globalmente a forma como a Coesão Territorial é interpretada pelas instituições da Administração Central/Regional e explanada nos diversos documentos de orientação estratégica consultados: i) desenvolvimento territorial, na ótica de promoção de ligações em rede e organização policêntrica do território; ii) desenvolvimento territorial, na ótica de equidade no acesso a Serviços de Interesse Geral; iii) governança territorial, na ótica de articulação de atores e políticas.

A ideia que decorre da primeira dimensão - que, globalmente reflete a ideia de promover uma organização policêntrica do território - não é recente. Disseminada essencialmente no âmbito do EDEC, surge como resposta às persistentes disparidades territoriais verificadas no espaço europeu e às discussões em torno do desenvolvimento territorial que eram dominadas pelo pensamento convencional centro/periferia, em que a área mais desenvolvida economicamente era circunscrita por Londres, Paris, Milão, Munique e Hamburgo (designado no próprio EDEC por Pentágono) e a restante (periferia) necessitava de auxílio urgentemente. De uma forma geral, alcançar um desenvolvimento mais policêntrico pressupõe uma organização territorial capaz de encorajar as ligações em rede e a cooperação, isto é, apta para promover uma maior complementaridade entre as áreas urbanas para que estas desempenhem um papel estrutural ao criar espaços de conexão e de integração interurbana e, ao mesmo tempo, desenvolver massa crítica ao nível económico global numa perspetiva cosmopolita. A Coesão Territorial surge, assim, associada à procura de um desenvolvimento urbano integrado e em rede.

O segundo elemento comum realça também a questão da organização territorial e das disparidades, mas desta feita no que respeita ao acesso aos Serviços de Interesse Geral. Por reconhecidamente desempenharem um papel chave na sociedade, seja por assegurarem a qualidade de vida dos cidadãos, seja porque representam os pilares de desenvolvimento social e económico dos territórios, esta questão há muito que vem 
sendo alvo de debate na procura de legitimar uma forte intervenção pública. Aliás, não é por acaso que a primeira vez que o princípio de Coesão Territorial surge formalmente - Tratado de Amesterdão (1997) - é com o principal intuito de moderar os efeitos associados à (tendência de) liberalização dos Serviços de Interesse Geral. De uma forma geral, a ideia que emerge é a de que a provisão equitativa destes serviços resultará em (ou contribuirá fortemente para) uma maior Coesão Territorial.

Por fim, o terceiro elemento está relacionado com a noção de governança, um termo crescentemente usado nos domínios académico e político especialmente a partir da década de 70 e atualmente considerado como fator crucial para a implementação de políticas públicas, embora o seu significado e os contextos onde é aplicado não sejam consensuais na literatura. A ideia específica de governança territorial refere-se essencialmente à procura de uma articulação mais eficiente, quer entre diferentes níveis de administração (ideia de governança multinível ou de cooperação/coordenação vertical, da escala europeia à escala local), quer entre entidades/atores do mesmo nível (ideia de cooperação/coordenação horizontal entre diversos atores, incluindo esferas pública, privada e terceiro sector), questões decisivas para a formulação de políticas e construção de estratégias coletivas territoriais. Esta cooperação institucional baseada numa visão partilhada sobre um mesmo território pressupõe, também, abordagens articuladas e integradas das várias dimensões sectoriais, ou seja, subentende a procura de coerência de políticas, também estas baseadas numa visão partilhada sobre um mesmo território. A noção de Coesão Territorial fica, deste modo, associada à ideia de articular, integrar e territorializar as políticas públicas - incorporando a dimensão territorial nas políticas sectoriais e articulando estas com as políticas de base territorial, contribuindo-se assim para uma maior sinergia entre diferentes políticas e para a maximização dos seus impactos territoriais.

\section{Notas finais}

A análise dos instrumentos de orientação estratégica em Portugal constitui uma boa indicação de como o princípio de Coesão Territorial está a ser interpretado pelas 
instituições públicas e outros atores-chave integrantes dos processos de tomada de decisão. Uma das principais mensagens que decorre da leitura efetuada é que as interpretações não são totalmente convergentes, nem são apresentadas medidas políticas explícitas em relação à operacionalização do princípio ${ }^{2}$. Apesar de tudo, foi possível identificar, à luz dos instrumentos analisados, três elementos caracterizadores deste princípio que se complementam e permitem traçar um referencial conceptual desenvolvimento territorial integrado e em rede, assegurando a igualdade de oportunidades no acesso a serviços e promovendo a articulação de atores e políticas -, quer para futuros debates académicos e políticos, quer para a formulação de políticas públicas, melhorando assim os processos de decisão com base no princípio de Coesão Territorial. Uma questão que se reveste de particular importância no período atual devido ao estabelecimento do novo enquadramento estratégico para o apoio estrutural comunitário 2014-2020, no qual se integram as opções estratégicas de desenvolvimento que os territórios definirem para esse período temporal.

Neste contexto, importa sublinhar que no próprio contributo formal (e institucionalmente transversal) das Autoridades Portuguesas para a consulta pública sobre o Livro Verde é mencionado que este poderia representar "um impulso fundamental para um debate amplo sobre a sua tradução na prática política das instituições europeias, das autoridades nacionais e regionais, dos parceiros económicos e sociais e dos demais atores da construção europeia e do desenvolvimento territorial" (MNE, 2008, p. 3). Ora, desde então, que o debate no sentido de clarificar e operacionalizar o conceito tem sido escasso, sob pena de se continuar na retórica discursiva ou de se assumir a visão demasiado abrangente que decorre da agenda europeia.

De um ponto de vista mais amplo, esta questão insere-se na necessidade de se efetivar um trabalho exaustivo e participado de sistematização de conceitos (em que se inclui a Coesão Territorial, mas não só) e modos de intervenção para que estes processos de

\footnotetext{
${ }^{2}$ É verdade que alguns dos instrumentos analisados, ao assumirem a importância da Coesão Territorial do ponto de vista declarativo e ao associarem implicitamente o seu conceito a outros domínios de intervenção (como sejam os já mencionados desenvolvimento policêntrico ou acesso a Serviços de Interesse Geral), apresentam algumas medidas de intervenção que podem, ainda que indiretamente, auxiliar a operacionalizar o conceito em estudo. Contudo, o argumento aqui apresentado refere-se a medidas de operacionalização explícitas do princípio de Coesão Territorial.
} 
transição (europeização) da agenda política europeia para a agenda nacional se concretizem de forma mais célere e eficaz.

Numa perspetiva mais específica, o caso já citado da Hungria pode servir como uma boa lição e um bom ponto de partida para uma reflexão contextualizada à realidade nacional neste período de crise económica e social. Justificava-se, pois, a elaboração de um manual de orientação estratégica (handbook) que proporcionasse, não só a clarificação e difusão das novas diretrizes comunitárias em matéria de ordenamento do território (designadamente as decorrentes da TA2020) junto das diversas instituições nacionais, mas também a construção de um quadro de referência para a ação e mobilização coletiva, esclarecendo as políticas e respetiva articulação e operacionalização, bem como o papel dos diversos intervenientes nas mais variadas escalas. O enfoque, influenciado pelo contexto social e económico atual, permitiria articular a dimensão territorial, espelhada nos diversos instrumentos nacionais, com as orientações estratégicas que decorrem, quer da Estratégia Europa 2020, quer do futuro quadro comunitário de apoio (Quadro Estratégico Comum), questões fundamentais no atual panorama da CE. E aqui o processo de aprendizagem desenvolvido no âmbito das discussões efetuadas em torno do EDEC pode servir como exemplo e estímulo para que, de facto, a construção de uma visão partilhada e pragmática do que se deve entender por Coesão Territorial se materialize.

A construção de um documento desta natureza poderia revelar-se útil por uma razão adicional: o desenvolvimento de uma listagem de indicadores capazes de auxiliar a tomada de decisões políticas baseadas no princípio de Coesão Territorial. A existência de tal listagem permitiria, certamente, uma melhor compreensão das orientações estratégicas por parte dos atores nacionais, dotando-os igualmente de uma maior capacidade de operacionalizar, monitorizar e avaliar os instrumentos, as práticas e os processos tendo por base este princípio. Também aqui há já um bom ponto de partida para um debate necessariamente coletivo. No recentemente publicado relatório final do Projeto INTERCO do programa ESPON (Dao, 2012) é possível encontrar uma listagem de indicadores capazes de caracterizar e mensurar a Coesão Territorial. Acresce que têm surgido algumas tentativas no âmbito da CE em tentar articular a dimensão territorial com o novo quadro de apoio comunitário e a Estratégia Europa 
2020, divulgando potenciais indicadores-chave capazes de traduzir essa intenção (vejase, a título de exemplo, Böhme et al, 2011).

O desafio está lançado, mas a maior ou menor capacidade de encontrar respostas é determinada pela capacidade dos principais atores individuais e coletivos conseguirem organizar-se em torno das sugestões aqui lançadas.

\section{Referências Bibliográficas}

Böhme, K.; Doucet, P.; Komornicki, T.; Zaucha, J.; Świątek, D. (2011). How to strengthen the territorial dimension of 'Europe 2020' and EU Cohesion Policy. Report based on the Territorial Agenda 2020 and prepared at the request of the Polish Presidency of the Council of the European Union, Warsaw.

Botka, M. et al (2009) Handbook on Territorial Cohesion - application of territorial approaches in developments supported by the public sector. NFGM - VATI, Budapest.

CEC (2011) Territorial Agenda 2020 - Towards an Inclusive, Smart and Sustainable Europe of Diverse Regions. Agreed at the Informal Ministerial Meeting of Ministers responsible for Spatial Planning and Territorial Development on 19th May 2011, Gödöllő, Hungary.

CEC (2008). Livro Verde sobre a Coesão Territorial Europeia - Tirar Partido da Diversidade Territorial. Comunicação da Comissão ao Conselho, ao Parlamento Europeu, ao Comité das Regiões e ao Comité Económico e Social Europeu, $\operatorname{COM(2008)~}$ 616 final, Bruxelas.

CEC (2007a) Agenda Territorial da União Europeia. Reunião Informal dos Ministros do Desenvolvimento Urbano e Coesão Territorial, Presidência Alemã da UE, Leipzig, 24 a 25 de Maio de 2007.

CEC (1999). European Spatial Development Perspective: Towards balanced and sustainable development of the territory of the European Union. Luxembourg: Office for Official Publications of the European Communities.

Colomb, C.; Santinha, G. (2012). European Union Competition Policy and the European Territorial Cohesion Agenda: An Impossible Reconciliation? State Aid Rules and Public 
Service Liberalization through the European Spatial Planning Lens. European Planning Studies, DOI:10.1080/09654313.2012.744384.

Cotella, G.; Janin-Rivolin, U. (2010). Institutions, discourse and practices: Towards a multidimensional understanding of EU territorial governance. 24th AESOP Annual Conference, Finland, 7-10 July.

Dao, H (Ed.) INTERCO: Indicators of territorial cohesion. Final report of ESPON Project 2013/3/2, ESPON Coordination Unit.

Davoudi, S. (2009). Territorial Cohesion, European Social Model and Transnational Cooperation. Planning Cultures in Europe: Decoding Cultural Phenomena in Urban and

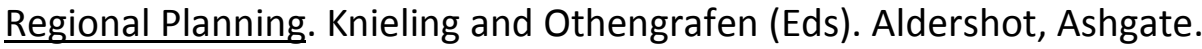

Davoudi, S.; Strange, I. (2009). Conceptions of Space and Place in Strategic Spatial Planning. London, Routledge.

Dühr, S.; Colomb, C.; Nadin, V. (2010). European Spatial Planning and Territorial Cooperation. London, Routledge.

Eser, T. (2009). From Disparities to Diversity - Territorial Cohesion in the European Union. New Disparities in Spatial Development in Europe: German Annual of Spatial Research and Policy. H. Kilper (Ed.). Berlin, Springer.

Estratégia de Lisboa-Portugal de Novo - Programa Nacional de Acção para o Crescimento e o Emprego 2005/2008 (2005). Presidência do Conselho de Ministros, Gabinete do Coordenador Nacional da Estratégia de Lisboa e do Plano Tecnológico.

Estratégia Nacional de Desenvolvimento Sustentável - ENDS 2015 (2008). Agência Portuguesa do Ambiente.

Faludi, A. (2010). Evolution and Future of EU Territorial Cohesion Policy. Encontro Annual 2010-Ad Urbem, Porto, Portugal, 26-27 Nov.

Faludi, A. (2007). Territorial Cohesion and the European Model of Society. Cambridge, Massachusetts, Lincoln Institute of Land Policy.

Featherstone, K.; Radaelli, C. (2003). The Politics of Europeanization. Oxford University Press. 
Ferrão, J. (2010). As Condições Sociais de Funcionamento da Política Pública de Ordenamento do Território. Programa de Investigação, provas de habilitação para o exercício de funções de coordenação científica, ICS-UL.

Ferrão, J. (2004). A emergência de estratégias transnacionais de ordenamento do território na União Europeia: reimaginar o espaço europeu para criar novas formas de governança territorial? Eure, XXX (89): 43-61.

Gorzelak, K. (2009). Cohesion and Convergence: Synonyms or Two Different Notions? Spatial Disparities and Development Policy. Kochendorfer-Lucius and Pleskovic (Eds). Berlin Workshop Series 2009, World Bank Publications.

Janin-Rivolin, U.; Faludi, A. (2005). Special issue Southern Perspectives on European Spatial Planning. European Planning Studies, 13(2): 195-332.

Knieling, J.; Othengrafen, F. (2009). Planning Cultures in Europe - Decoding Cultural Phenomena in Urban and Regional Planning. Farnham, Ashgate.

Luukkonen, J.; Moilanen, H. (2012). Territoriality in the Strategies and Practices of the Territorial Cohesion Policy of the European Union: Territorial Challenges in Implementing "Soft Planning". European Planning Studies, 20(3): 481-500.

MNE (2008). Contributo das Autoridades Portuguesas para a Consulta Pública sobre o Livro Verde sobre a Coesão Territorial Europeia - Tirar Partido da Diversidade Territorial. Gabinete da Secretária de Estado dos Assuntos Europeus, MNE.

Mourato, J.; Rosa Pires, A. (2007). Portugal e a perspectiva de desenvolvimento do Espaço Europeu: o EDEC como institucionalização de um discurso de mudança. Sociedade e Território, 40: 34-42.

Nordregio (2009). The Potential for Regional Policy Instruments, 2007-2013, to Contribute to the Lisbon and Goteborg Objectives for Growth, Jobs and Sustainable Development. Final Report to the European Commission, Directorate-General for Regional Policy, Evaluation Unit.

Olsen, J. (2002). The Many Faces of Europeanization. JCMS, 40(5): 921-52.

Plano Estratégico Nacional de Desenvolvimento Rural - PENDR 2007-2013 (2009). Gabinete de Planeamento e Políticas, MAMAOT. 
Plano Regional de Ordenamento do Território - Alentejo (2010). CCDR Alentejo, MAOTDR.

Plano Regional de Ordenamento do Território - Algarve (2007). CCDR Algarve, MAOTDR.

Plano Regional de Ordenamento do Território - AML (2010). Proposta, CCDR LVT, MAOTDR.

Plano Regional de Ordenamento do Território - Centro (2011). Proposta, CCDR Centro, MAOTDR.

Plano Regional de Ordenamento do Território - Norte (2009). Proposta, CCDR Norte, MAOTDR.

Plano Regional de Ordenamento do Território - OVT (2009). CCDR LVT, MAOTDR.

Política de Cidades POLIS XXI 2007-2013 (2008). Gabinete do Secretário de Estado do Ordenamento do Território e das Cidades, MAOTDR.

Quadro de Referência Estratégico Nacional - Portugal 2007-2013 (2007). Observatório do QCA III, MAOTDR, Lisboa.

Ricz, J. et al (2010). Handbook for the national implementation of the Territorial Agenda of the European Union: the case of Hungary. NFGM - VATI, Budapest.

SEOTC (2005) PROT 2006: Orientações para a elaboração dos Planos Regionais de Ordenamento do Território. MAOTDR, Lisboa.

Servillo, L. (2010). Territorial Cohesion Discourses: Hegemonic Strategic Concepts in European Spatial Planning. Planning Theory \& Practice, 11(3): 397-416.

Sykes, O. (2011). Investigating Sub-state Interpretations of European Territorial Cohesion: The Case of the United Kingdom. International Planning Studies, 16(4): 377396.

Van Well, L. (2012). Conceptualizing the Logics of Territorial Cohesion. European Planning Studies, 20(9): 1549-1567. 